\title{
Biodecolorization and Biodegradation of Azo Dye Reactive Orange-16 by Marine Nocardiopsis sp.
}

\author{
Vaibhavi Chittal ${ }^{1}$, Magaly Gracias ${ }^{1}$, Anagha Anu ${ }^{1}$, Purbasha Saha ${ }^{1}$, K.V. Bhaskara Rao ${ }^{\text {1,* }}$ \\ ${ }^{1}$ Biomolecules Laboratory, Technology Tower (TT 635), Vellore Institute of Technology (VIT) University, Vellore- \\ 632014, Tamil Nadu, India \\ * Corresponding author: K.V. Bhaskara Rao, Biomolecules Laboratory, Technology Tower (TT 635), Vellore Institute of Technology (VIT) \\ University, Vellore- 632014, Tamil Nadu, India. Mobile: +91-9894350824; Fax: +91-4162243092; E-mail: kvbhaskararao@vit.ac.in
}

\begin{abstract}
Background: Azo dyes are xenobiotic compounds that have bioaccumulated in the environment due to escalated industrial development. These are hazardous in nature, possessing carcinogenic and mutagenic effects on human beings.

Objectives: The perspective of the present study was to isolate and to determine azo dye (Reactive Orange-16) degrading potential of marine actinobacteria isolated from sediment samples of Port Blair, India.

Material and Methods: Actinobacteria with dye decolorization potential were isolated from sea sediment samples. The actinobacterial isolate with the highest dye decolorizing percentage was identified with the help of phenotypic, biochemical and molecular studies. The different physico-chemical parameters for dye decolorization were also optimized. The nature of decolorization by the potent isolate was determined with the help of High Performance Liquid chromatography (HPLC) and Fourier Transformed Infrared spectroscopy (FTIR) techniques. Further the toxicity of RO-16 decolorized products was investigated with the help of phytotoxcity assay.

Results: Out of six actinobacterial isolates, VITVAMB 1 possessed the most efficient RO-16 decolorization property. It decolorized $85.6 \%$ of RO-16 $\left(250 \mathrm{mg} \mathrm{L}^{-1}\right)$ within $24 \mathrm{hrs}$. Isolate VITVAMB 1 was identified to be Nocardiopsis sp. Maximum dye decolorization occurred at $\mathrm{pH} 8$, temperature $35^{\circ} \mathrm{C}, 3 \%$ salt concentration and a dye concentration of $50 \mathrm{mg} \mathrm{L}^{-1}$.

Conclusions: The nature of decolorization by Nocardiopsis sp. was biodegradation. Additionally, the degraded dye metabolites were found to be less toxic than pure dye. The high decolorization potential of VITVAMB 1 and the low toxicity of its degradation products make it a prospective dye removal system. The marine origin of VITVAMB 1 also makes it an attractive source for novel azo dye reducing enzymes.
\end{abstract}

Keywords: Biodegradation, Environmental; Spectroscopy, Fourier Transform Infrared; Chromatography, High Pressure Liquid; Reactive Orange-16

\section{Background}

Dye is a natural or synthetic substance used to add color. Its application in an aqueous solution must be followed by a mordant to increase the fastness of the dye on the fiber. Dye sticks to compatible surfaces by solution, by covalent bond formation or complex formation with salts or metals or by mechanical treatment (1). Such substances with substantial coloring ability find daily application in a wide range of industries including food, textile, pharmaceutical, cosmetics, photographic, and paper industries (2). Textile industries are an important contributor to the economic backbone of various nations. However, they are the major cause of environmental pollution such as land, air, water bodies and hazardous to living organisms. In the last decade, another element introduced for the environment friendliness of the finished merchandise, was the ban on certain azo dyes, which are known or suspected to be carcinogenic (3). More than 1,00,000 synthetic dyes exist so far and over $7 \times 105$ tons are commercially produced annually worldwide (2). Azo dyes comprise approximately $50 \%$ of the total dye production, and are the largest class among the synthetic dyes. They belong to the class of water soluble reactive dyes along with other dyes as anthraquinone, formazane and phthalocyanine. Azo dyes dominate the commercial market mainly because of the ease of their production 
and the variety of colors they provide. In contrast to the organic pigments, color imparted by dyes are resistant to breakdown. The recalcitrant nature of the azo dyes are imparted by the presence of the azo group $(\mathrm{N}=\mathrm{N})$ which are not found in nature (4). The presence of azo group as a chromophore along with other auxochromes such as amine $(\mathrm{NH} 2)$, carboxyl $(\mathrm{COOH})$, sulfonate $(\mathrm{SO} 3 \mathrm{H})$ and hydroxyl $(\mathrm{OH})$ is responsible for the vivid colors supplied by the azo dyes. Current knowledge about the long-term hazardous effects of dyes is still limited. Many disperse dyes in marine systems also show a connection to the bioaccumulation (5).

Different dyes are classified based on their chemical structure or chromophore. The classification of the Reactive Orange-16 (RO-16) dye used in this study is given in Table 1.

Table 1. The classification of the RO-16

\begin{tabular}{|c|c|c|c|c|}
\hline Name & Chemical formula & Molar mass $\left(\mathrm{g} \mathrm{mol}^{-1}\right)$ & Structure & $\lambda_{\max }(\mathrm{nm})$ \\
\hline RO-16 & $\mathrm{C}_{2} \mathrm{OH}_{17} \mathrm{~N}_{3} \mathrm{Na}_{2} \mathrm{O}_{11} \mathrm{~S}_{3}$ & 617.54 & & 492 \\
\hline
\end{tabular}

$\mathrm{RO}-16$ is commonly used in textile industries on a daily basis to dye cellulosic fibers and has poor fixation efficiency. A large amount of the dye is released along with the industrial effluents. Hence RO-16 was chosen for this study.

Due to low biodegradability of dyes, conventional effluent treatment systems are inefficient in treating industrial wastewater (6). The current physical or chemical treatment processes used includes coagulation, adsorption, oxidation, flocculation, filtration and electrochemical methods (7). Biological treatment of dye containing effluents offer an ecofriendly and low cost method to counteract pollution. There have been several reports of organisms which degrade dyes such as bacteria, fungi, yeast and actinomycetes (8). The biodecolorization of azo dyes involves either biodegradation (cleavage of azo bond) or biosorption (using living or dead biomass) process (9).

The marine ecosystem provides a unique and diverse range of actinomycetes. They are widely distributed in the intertidal zones, seawater, animals, plants, sponges, and also in ocean sediments. Marine environment is extremely different from terrestrial environment and is an important source of isolation of new species of actinomycetes producing novel bioactive compounds (10). Earlier, reports have been made on the degradation of hydrocarbons (11), explosives (12), chlorinated solvents (13), plasticizers (14) and azo dyes (15) by terrestrial actinomycetes. However, marine actinomycetes were less explored for their ability in biodegradation of hazardous dyestuff. Hence, in this study marine actinobacteria have been utilized for the biodecolorization and degradation of azo dyes.

\section{Objectives}

The aim of this study was to explore the marine environment for the isolation of actinobacteria capable of decolorizing azo dye Reactive orange- 16 and also to determine the nature of decolorization.

\section{Materials and Methods}

\subsection{Chemicals}

Azo dye was obtained from a textile industry in Mysore, Karnataka, India $\left(12.2958^{\circ} \mathrm{N}, 76.6394^{\circ} \mathrm{E}\right)$. The dye used in this study was C.I. RO-16.

Starch casein agar (SCA), glucose, peptone, manganese chloride $\left(\mathrm{MnCl}_{2} \cdot 4 \mathrm{H}_{2} \mathrm{O}\right)$, ethyl acetate, potassium bromide $(\mathrm{KBr})$ were purchased from HiMedia Laboratories Pvt. Ltd., India. Soluble starch, yeast extract, beef extract, glycerol, calcium carbonate $\left(\mathrm{CaCO}_{3}\right)$, zinc sulphate $\left(\mathrm{ZnSO}_{4}\right)$, copper sulphate $\left(\mathrm{CuSO}_{4} .5 \mathrm{H}_{2} \mathrm{O}\right)$, ferrous sulphate $\left(\mathrm{FeSO}_{4} \cdot 7 \mathrm{H}_{2} \mathrm{O}\right)$, sodium nitrate $\left(\mathrm{NaNO}_{3}\right)$ and mercuric chloride $\left(\mathrm{HgCl}_{2}\right)$ were obtained from Sisco Research Laboratories Pvt. Ltd., India. HPLC grade carbinol was procured from Thomas Baker (chemicals) Pvt. Ltd, India. All the chemicals used to carry out these experiments were of highest purity.

\subsection{Sample Collection}

Marine sediment samples were collected from Port Blair, India $11^{\circ} 40^{\prime} 06^{\prime \prime} \mathrm{N} 92^{\circ} 44^{\prime} 16^{\prime \prime}$ E. Samples were collected in sterilized containers, and plastic bags. For further use, it was transferred to the laboratory and stored at a temperature of $4^{\circ} \mathrm{C}$.

\subsection{Isolation and Screening of Actinobacteria}

Sediment sample was serially diluted and $0.1 \mu \mathrm{L}$ aliquots were plated on SCA plates. Inoculated plates were incubated at room temperature for a period of 7-10 days. Isolates with distinct colony morphology were selected and subcultured repeatedly on SCA plates to obtain pure cultures (16).

Primary screening of the isolates was performed in Soluble Starch broth (composed of starch $25 \mathrm{~g}$, glucose $10 \mathrm{~g}$, yeast extract $2 \mathrm{~g}$, trace salt solution 1 $\mathrm{mL}, \mathrm{CaCO}_{3} 3 \mathrm{~g}$, distilled water $500 \mathrm{~mL}$ and sea water $500 \mathrm{~mL}$ ) as well as fermentation broth (consisting of glycerol $70 \mathrm{~mL}$, glucose $30 \mathrm{~g}$, beef extract $30 \mathrm{~g}$, peptone $80 \mathrm{~g}$, NaNO3 $20 \mathrm{~g}$, and $1 \mathrm{~L}$ of sea water, 
maintained at $\mathrm{pH}$ 7) for 5-7 days at room temperature. Broth cultures were then observed for decolorization (17).

\subsection{Decolorization Assay of Actinobacterial Isolates Against RO-16}

Decolorization of the broth cultures were analyzed by UV-Vis Spectrophotometer (Hitachi U-2800) at an absorbance maximum $\left(\lambda_{\max }\right)$ of $492 \mathrm{~nm}$ for RO-16. Actinobacterial isolates were cultured in fermentation media consisting of RO-16 at a concentration of $250 \mathrm{mg}$ $\mathrm{L}^{-1}$. Culture broths were then incubated at $28^{\circ} \mathrm{C}$ for a period of 7 days. After incubation, culture broths were centrifuged at $6,708 \times \mathrm{g}$ for $15 \mathrm{~min}$. Supernatant was collected and analyzed spectrophotometrically for dye decolorization at regular time intervals. Negative control and blank was maintained. The extent of dye decolorization was quantified using the following formula (8):

$$
\% \text { Decolorization }=\frac{\text { Initial absorbance }- \text { Final absorbance }}{\text { Initial absorbance }} \times 100
$$

\subsection{Optimization of Dye Decolorization Process}

Some of the physico-chemical factors which might have an effect on dye decolorization process were investigated. The maximum decolorization percentage was monitored by varying the $\mathrm{pH}(\mathrm{pH} 4,5,6,7,8,9,10)$, temperature $\left(25^{\circ} \mathrm{C}, 35^{\circ} \mathrm{C}, 45^{\circ} \mathrm{C}, 55^{\circ} \mathrm{C}\right), \quad \mathrm{NaCl}$ concentration $(1 \%, 2 \%, 3 \%, 4 \%, 5 \%)$ and dye concentration $\left(50 \mathrm{mg} \mathrm{L}^{-1}, 100 \mathrm{mg} \mathrm{L}^{-1}, 150 \mathrm{mg} \mathrm{L}^{-1}, 200\right.$ $\mathrm{mg} \mathrm{L}^{-1}, 250 \mathrm{mg} \mathrm{L}^{-1}$, and $\left.300 \mathrm{mg} \mathrm{L}^{-1}\right)$.

\subsection{Identification of the Potential Dye Degrading Actinobacteria}

The potential isolate VITVAMB 1 with high dye decolorizing ability was chosen for identification. Phenotypic characteristics (aerial mass color, mycelial morphology, gram character, acid-fastness) were observed and biochemical tests (catalase, oxidase, nitrate reduction, citrate utilization, starch hydrolysis, gelatin liquefaction, melanin production, decomposition of xanthine, hypoxanthine, esculine, urea, and carbohydrate fermentation tests) were performed. Phenotypic and biochemical characterization was performed as described by Shirling \& Gottileb (1966), and Bergey's manual of determinative bacteriology (18). Further molecular studies (16S rRNA gene sequencing) was done to identify the isolate to the species level. The $16 \mathrm{~S}$ rRNA gene was isolated and amplified. The resulting gene sequence was then aligned with closely related sequences from NCBI using MUSCLE software program. Further, a phylogenetic tree was constructed using the software MEGA 5.

3.7. Analysis of Degraded Metabolites by Fourier Transform-Infrared spectroscopy (FT-IR), and High Pressure Liquid Chromatography (HPLC)
The degraded metabolites obtained after dye degradation were extracted by solvent extraction method using ethyl acetate. These extracted metabolites were then dried in a rotary evaporator. The dried metabolites thus obtained were used for further analysis. The dried sample was used directly for FT-IR analysis. FT-IR was carried out in mid IR range of $400-4000 \mathrm{~cm}^{-1}$ at a scan speed of 16. The dried metabolite was uniformly mixed with spectroscopically pure $\mathrm{KBr}$ in a ratio of $1: 9$, the mixture was fastened firmly in sample holder, and then analyzed.

HPLC analysis of the ethyl acetate extracted sample and that of the pure dye was carried out (Waters model no. 1525) with UV-detector set at $492 \mathrm{~nm}$. The stationary phase was a $\mathrm{C}_{18}$ column $(4.6 \times 250 \mathrm{~mm})$ and the mobile phase was HPLC grade carbinol/water $(55: 45 \mathrm{v} / \mathrm{v})$. The flow rate was $0.8 \mathrm{~mL} \mathrm{~min}^{-1}$ and the run time was 20 $\min$.

\subsection{Phytotoxicity Study}

The phytotoxicity assay was performed using seeds of Vigna radiata (moong dal) in order to investigate the toxicity of pure dye (RO-16) and its degraded metabolites. The concentration of RO-16 and its degraded metabolites used for this study was $100 \mathrm{ppm}$. Seeds treated with distilled water was used as control. The seeds were first surface sterilized using $1 \% \mathrm{HgCl} 2$ solution and then cleansed with distilled water for further use. Seeds were then kept on wet cotton placed in a petridish and regularly treated with a fixed volume of dye, degraded metabolite and control was maintained with distilled water for a period of 7 days. After 7 days percentage of the germinated seeds was calculated from each set. The shoot length of the germinated seeds was also measured (19).

\subsection{Statistical Analysis}

In this study were performed in triplicates. Decolorization assay and optimization studies were statistically analyzed using one way as well as two way ANOVA. The results were established based on probabilities and significance was considered at $95 \%$ confidence level.

\section{Results}

4.1. Isolation and Screening of Actinobacteria for Decolorization of $\mathrm{RO}-16$

A total of six actinobacterial isolates (VITVAMB 1, VITVAMB 2, VITVAMB 3, VITVAMB 4, VITVAMB 5 , VITVAMB 6) were recovered from the marine sediment samples. Among them only three isolates showed the dye decolorizing potential (VITVAMB 1, VITVAMB 4 and VITVAMB 6) during primary screening. Further decolorization assay was performed using VITVAMB 1, VITVAMB 4 and VITVAMB 6.

\subsection{Decolorization Assay}


The actinobacterial isolate VITVAMB 1 showed $85.6 \%$ of decolorization of RO-16 within $24 \mathrm{~h}$. Whereas, VITVAMB 6 and VITVAMB 4 showed a decolorization of $52 \%$ and $42.34 \%$ of RO-16 with 24 h respectively. The isolate VITVAMB 1 showed rapid increase in percentage of decolorization after $12 \mathrm{~h}$ and the percentage increased with time elapsed. Comparatively, VITVAMB 4 and VITVAMB 6 showed a gradual increase in decolorization (Fig. 1).

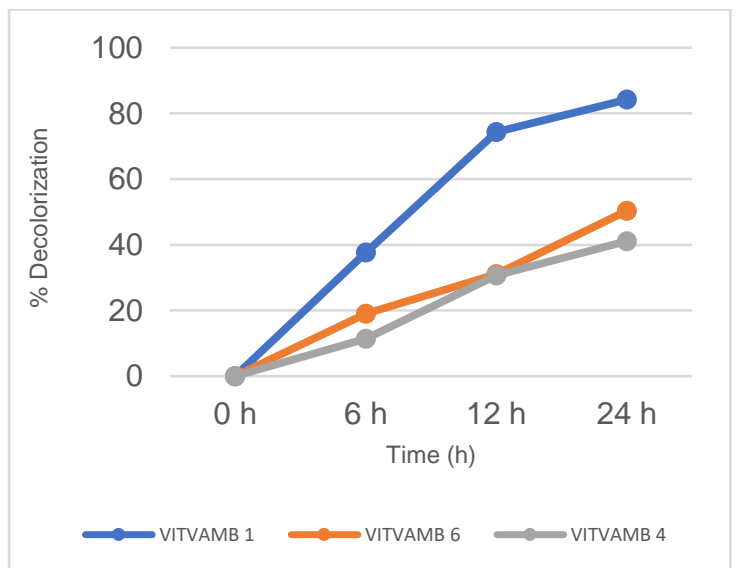

Figure 1. Decolorization percentage of RO-16 by VITVAMB 1, VITVAMB 6 and VITVAMB 4 at specific time intervals

\subsection{Optimization of Dye Decolorization}

The varying physico-chemical parameters had a considerable impact on the dye decolorization percentage. The effect of different $\mathrm{pH}$ showed highest decolorization of $94.5 \%$ at $\mathrm{pH} 8$ followed by $86 \%$ at $\mathrm{pH} 7$. Decolorization was greatly reduced at acidic $\mathrm{pH}$ range as well as alkaline $\mathrm{pH}$ range (Fig. 2a). When temperature was varied, maximum decolorization of $94.13 \%$ occurred at $35^{\circ} \mathrm{C}$. Isolate VITVAMB 1 was capable of maintaining a good decolorization potential within the temperature range of $25-45^{\circ} \mathrm{C}$. However decolorization was reduced to almost half on increasing the temperature to $55^{\circ} \mathrm{C}$ (Fig. 2b). Salt concentration of $3 \%$ produced the highest decolorization of 94.62\%. Comparable decolorization (90.42\%) occurred at $2 \%$ salt concentration. Dye decolorization was greatly reduced at higher salt concentrations of $4 \%$ and 5\% (Fig. 2c). The effect of varying dye concentration was also studied and good dye decolorization was observed till $250 \mathrm{mg} \mathrm{L}$ ${ }^{1}$. Decolorization gradually decreased with increasing dye concentration and highest decolorization (95.073\%) occurred at the lowest dye concentration $\left(50 \mathrm{mg} \mathrm{L}^{-1}\right)$. Dye decolorization was lowered to $56.39 \%$ at $300 \mathrm{mg} \mathrm{L}^{-1}$ (Fig. 2d).

\subsection{Identification of the Potential Dye Degrading Actinobacteria}

The potential isolate VITVAMB 1 was identified to belong to the genus Nocardiopsis when subjected to phenotypic and biochemical characterization. The aerial mass color was white and was abundant, fragmenting and branched in morphology. The substrate mycelium was long and densely branched, fragmented into coccoid shape. It was gram positive and non- acid fast bacteria. It showed positive reaction for oxidase, catalase, starch hydrolysis, nitrate reduction, citrate utilization and gelatine liquefaction. It was capable of decomposing xanthine, hypoxanthine and esculine, but did not decompose urea. Melanin production was not identified. Among the sugars, VITVAMB 1 utilized glucose, rhamnose, maltose, fructose, galactose, starch, but was incapable of fermenting sucrose, arabinose, inositol, sorbitol.

Based on 16S rRNA molecular studies VITVAMB 1 was identified to be Nocardiopsis dassonvillei sp. Basic local alignment search tool (BLAST) was used to analyze the consensus sequence of VITVAMB 1. Strain VITVAMB 1 had close phylogenetic affiliation to the genus Nocardiopsis. The phylogenetic tree formed shows that strain VITVAMB 1 has $100 \%$ similarity with Nocardiopsis dassonvillei subsp. Albirubida strain NBRC 13392 (Fig. 3). The 16S rRNA gene sequence of VITVAMB 1 is available in the NCBI database with the accession number MF616329.1.

\subsection{FT-IR Analysis}

The FTIR analysis of both the pure dye RO-16 and decolorized dye product were carried out to identify and compare the different functional groups present in both the compounds. Spectrum of the pure dye showed -OH group at $3265.49 \mathrm{~cm}^{-1}$, while 29339.73 and $2879.72 \mathrm{~cm}^{-}$ ${ }^{1}$ represented C-H stretch respectively. C-N stretch was observed at $1035.77 \mathrm{~cm}^{-1}, 993 \mathrm{~cm}^{-1}$ corresponded to $\mathrm{C}=\mathrm{H}$ out of frame vibration and $850 \mathrm{~cm}^{-1}$ for S-OR ester. Signature azo group $(\mathrm{N}=\mathrm{N})$ of the dye was observed at $1637.56 \mathrm{~cm}^{-1}$ (Fig. 4a).

On the contrary, FT-IR spectrum of the decolorized dye product showed changes in the position of the peak formation. There was a shift of $\mathrm{OH}$ group to 3300.20 $\mathrm{cm}^{-1}$, and the azo group to $1635.654 \mathrm{~cm}^{-1}$ (Fig. 4b). The absence of all other peaks shows the distortion of the compound, thus it can be concluded that the dye structure has been degraded.

\subsection{HPLC Analysis}

The HPLC chromatogram of the pure dye RO-16 at the beginning of static incubation has been shown in Figure 5(a). The chromatogram shows a sharp major peak with a retention time of $1.756 \mathrm{~min}$. After decolorization occurred, the chromatogram of the degraded dye metabolite showed a considerable decrease of the major peak. After degradation a major peak was formed at $2.552 \mathrm{~min}$ and two other peaks were formed at $2 \mathrm{~min}$ and $3.5 \mathrm{~min}$ respectively (Fig. $5 \mathbf{b})$. Disappearance of the major peak of the pure dye 
RO-16 and appearance of new peaks at different retention time in the HPLC chromatogram of

A

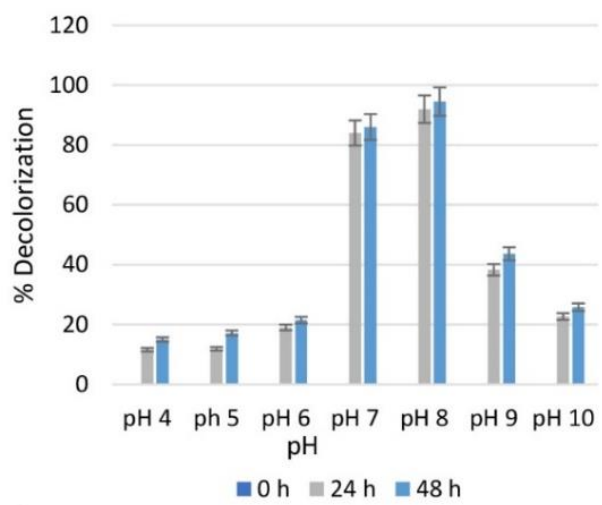

C

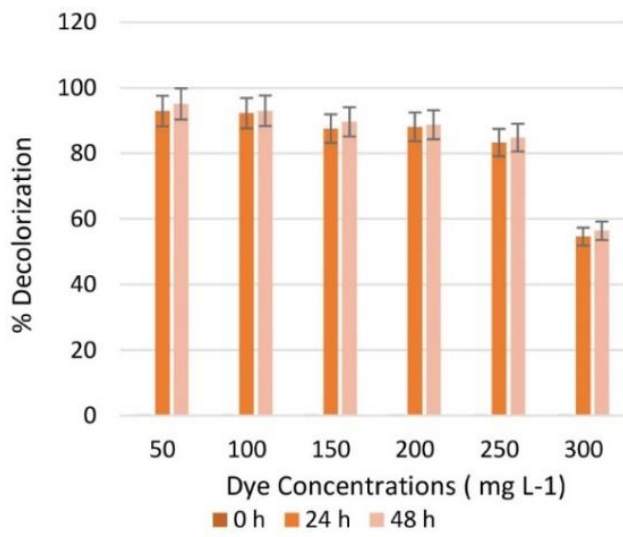

degraded dye metabolite indicates degradation of the dye.

B

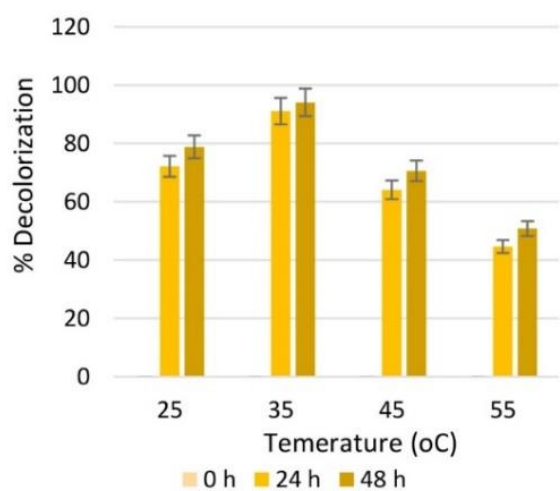

D

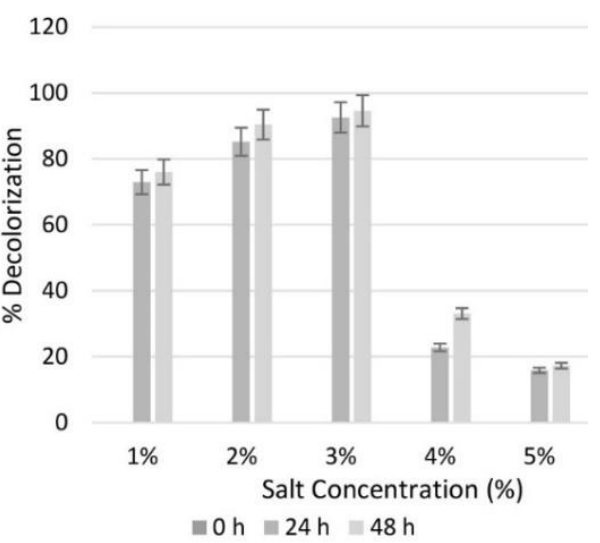

Figure 2. Optimization of Dye decolorization under different physico-chemical parameters (a) $\mathrm{pH}$; (b) temperature; (c) salt concentration; (d) dye concentration

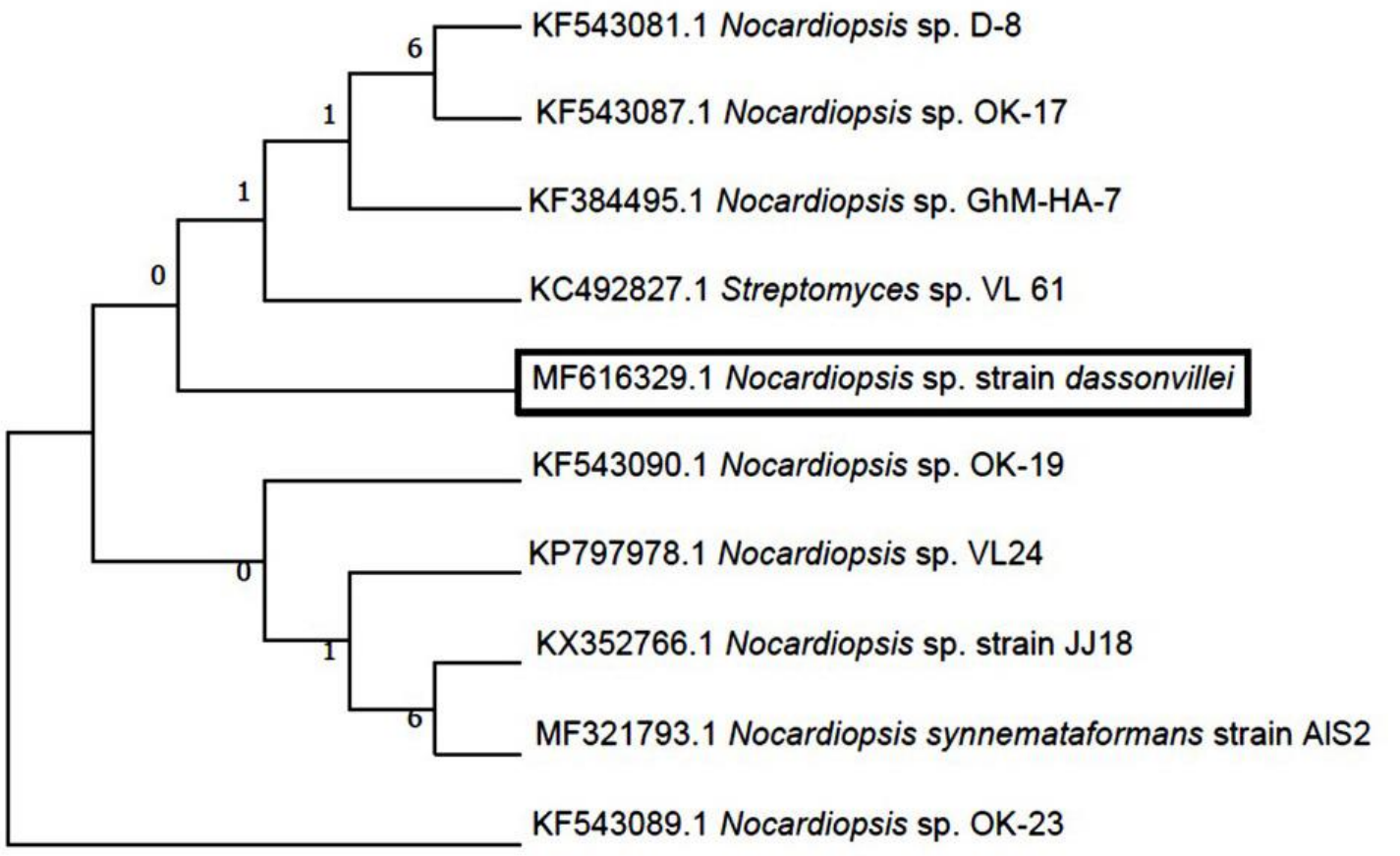

Figure 3. Phylogenetic Tree of Isolate VITVAMB 1 
A

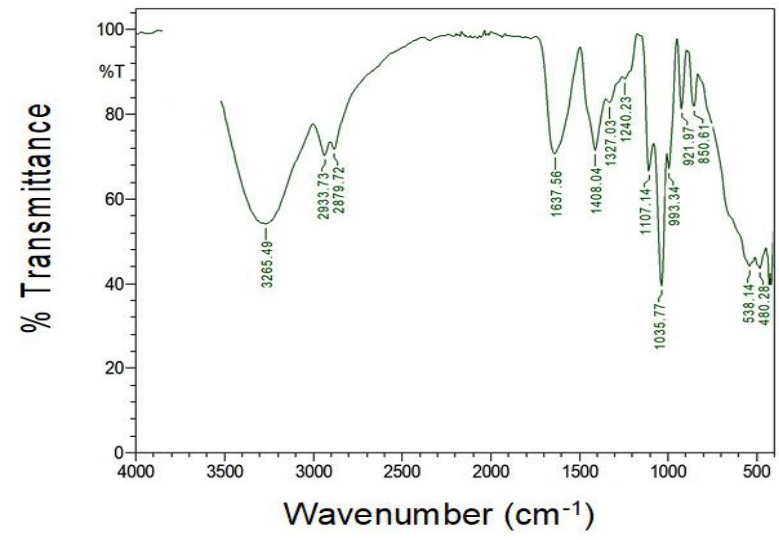

B

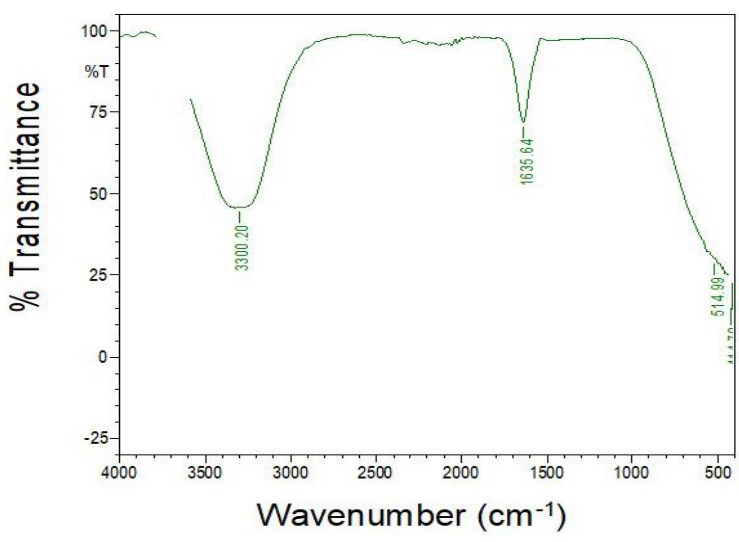

Figure 4. FT-IR Analysis A) Spectrum of Pure Dye RO-16; B) Spectrum of Degraded RO-16 Metabolite by VITVAMB 1

A

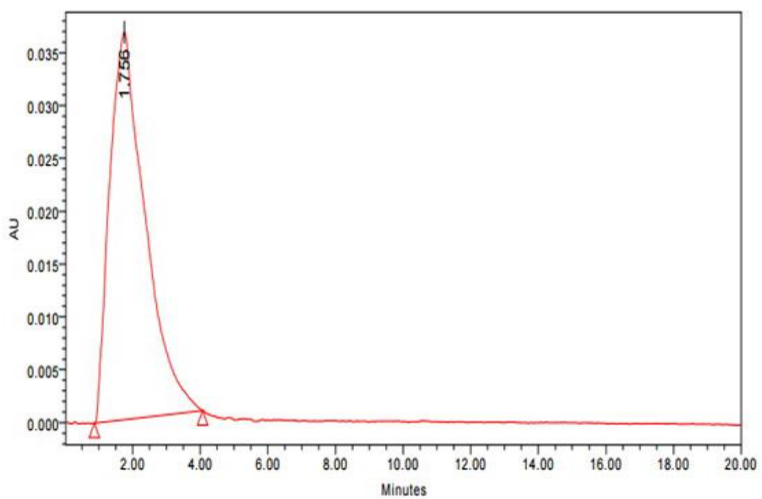

B

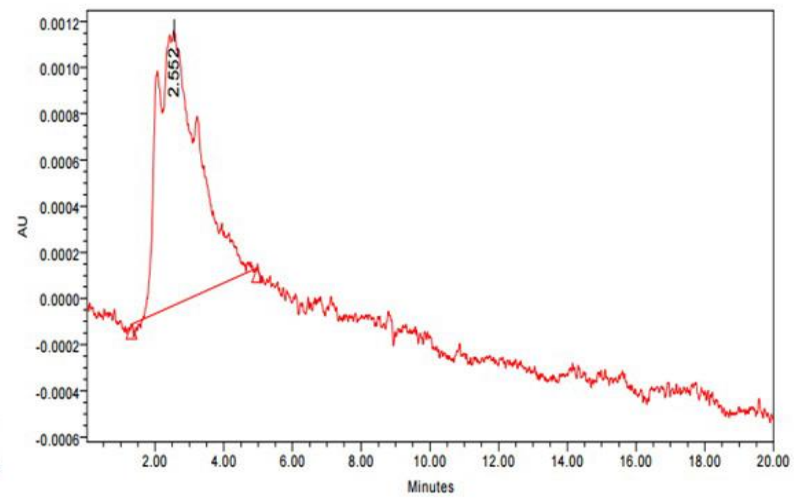

Figure 5. HPLC Chromatogram A) Pure Dye RO-16; B) Degraded Dye Metabolite of RO-16

\subsection{Phytotoxicity Study}

Phytotoxicity assay results to determine the toxicity of pure dye RO-16 and degraded dye produtcs conducted with seeds of Vigna radiata. Seeds which underwent treatment with degraded dye metabolites (100 ppm) and control treatment showed a germination rate of $50 \%$ and $95 \%$ respectively, whereas seeds treated with RO-16 (100 ppm) showed a very low germination rate of only $10 \%$. Similar trend was observed for shoot length analysis. Seeds treated with RO-16 had very less shoot length of about $0.13 \pm 0.035 \mathrm{~cm}$, while seeds treated with degraded dye metabolite showed an intermediate shoot length of $0.8 \pm 0.153 \mathrm{~cm}$, which were on par with the control seeds with a shoot length of $1.1 \pm 0.231 \mathrm{~cm}$.

Values represented in the assay were mean of three experiments \pm SEM, and were found to be significantly different from the control treatment at $\mathrm{P}<0.05$, by one way analysis of variance (ANOVA).

\section{Discussion}

Microbial clean-up of toxic pollutants in the environment is a foremost and important area of research owing to the rising levels of environmental pollution. Azo dyes are the major commercial dyes used in a wide variety of industries and are toxic xenobiotic compounds. Their recalcitrant nature resists their biodegradation. In the present study, actinobacterial isolates from the marine environment were studied to examine their potential to decolorize and degrade azo dye RO-16. A total of six marine actinobacterial isolates were obtained and three of the isolates (VITVAMB 1, VITVAMB 6 and VITVAMB 4) showed dye decolorization ability. In a similar study, actinomycetes were obtained from marine sediments and three isolates belonging to the genera of Micromonospora sp., Streptomyces sp. and Micropolyspora sp. showed the ability to decolorize Amido Black (20). Another study reported the isolation of 15 different strains of actinomycetes, out of which Nocardia sp. demonstrated dye decolorizing ability of Congo Red (21). In the present study the isolate VITVAMB 1 showed a decolorizing potential of $85.6 \%$ at a dye concentration of $250 \mathrm{mg} \mathrm{L}-1$ (RO-16) within $24 \mathrm{~h}$ and was identified to be Nocardiopsis sp. strain dassonvillei. Previously, Shobana and Thangam (22) reported the decolorizing ability of Nocardiopsis alba isolated from acclimated sludge and dying waste water. $N$. alba was able to decolorize $83-85 \%$ of the dye RO-16 at a concentration of $250 \mathrm{mg} \mathrm{L}-1$ which is on par with the current study. In 
another study, a novel marine actinomycetes strain Streptomyces sp. VITDDK3 showed 98\% decolorization of azo dye Reactive Red 5B at a concentration of $50 \mathrm{mg}$ $\mathrm{L}^{-1}$ (23). Although decolorization was higher in this case, but the concentration of dye used was much less than that of the present study. Several researches proved that physico-chemical parameters as $\mathrm{pH}$, temperature, salinity, cations, anions, biological oxygen demand, chemical oxygen demand have profound effect on degradation of various environmental pollutants (19, $24)$. In this study the consequence of varying $\mathrm{pH}$, temperature, salt concentration and dye concentrations on dye decolorization were studied. Highest decolorization occurred at a slightly alkaline $\mathrm{pH}$ of 8 . In an earlier report, Streptomyces krainskii SUK-5 showed complete decolorization of Reactive Blue-59 at $\mathrm{pH} 8$ (25). Previous studies have also proved that actinobacterial enzymes show optimal activity at $\mathrm{pH} 8$ $(26,27)$. Industrial processes utilizing reactive dyes operate at alkaline $\mathrm{pH}$. Thus the ability of VITVAMB 1 to show maximum decolorization at an alkaline $\mathrm{pH}$ can be beneficial for industrial application. Temperature plays crucial role in dye degradation as observed in previous studies (28-30). In the present study maximum decolorization occurred at $35^{\circ} \mathrm{C}$. Similar studies reported that Streptomyces sp. showed optimal dye degradation at a temperature of $40^{\circ} \mathrm{C}(30) . N$. alba reportedly showed maximum decolorization of RO-16 at a temperature of $30^{\circ} \mathrm{C}(22)$. Textile wastewater often consists of heavy amounts of inorganic salts especially chlorides and sulfates (31). In this research, the effects of varying concentrations of sodium chloride on dye decolorization was studied. Dye decolorization showed a gradual increase of decolorization with increasing salt concentration. Highest decolorization (94.62\%) occurred at $3 \%$ salt concentration. However, higher salt concentrations of $4 \%$ and $5 \%$ showed a sudden decrease in decolorization potential. Similar results were reported by (19). Dye concentration was also varied and dye decolorization gradually decreased with increased dye concentration. Highest decolorization (95.07\%) occurred at lowest concentration $\left(50 \mathrm{mg} \mathrm{L}^{-1}\right)$. Isolate VITVAMB 1 showed good decolorization potential till a dye concentration of $250 \mathrm{mg} \mathrm{L}^{-1}$. Dye decolorization diminished to $56.39 \%$ at $300 \mathrm{mg} \mathrm{L}^{-1}$. The decrease in decolorization ability with escalating dye concentration can be ascribed to be the toxic effects of pure dye imposed on the microbial cells. Similar effect was observed in actinomycete Georgenia sp. CC-NMPTT3. Maximum decolorization of $94.2 \%$ occurred at the lowest concentration ( $50 \mathrm{mg} \mathrm{L}^{-1}$ ) and decolorization decreased to $85.24 \%$ at $500 \mathrm{mg} \mathrm{L}^{-1}$ (32). Further, the mechanism of dye decolorization was biodegradation, which was evident from the results of FT-IR, and HPLC analysis. FTIR spectra of the extracted metabolite of dye degradation showed absence of major functional groups which were present in the spectra of the pure dye. This indicates that the dye molecule was degraded. HPLC chromatogram of the degraded dye metabolite showed displacement of the major peak and formation of two other peaks at different retention times when compared to that of the pure dye RO-16. Several reports have been made earlier, which used HPLC and FT-IR to identify dye degradation. In 2009, Saratale et al. showed the biodegradation of Scarlet $\mathrm{R}$ by a bacterial consortium using FT-IR and HPLC (33). Similarly, Kalyani et al. (2009) used FT-IR and HPLC to identify the degradation of the dye Reactive Red 2 by Pseudomonas sp. SUK1 (34). It is essential to prove that the degraded dye metabolites so produced are non-toxic for its successful field application. Phytotoxicity assay provides certain advantages as it is economical, takes less time, has similar chromosomal morphology to mammals, and produces similar response to mutagens. Numerous phytotoxicity assays had been conducted earlier with seeds of plants such as Sorghum vulgare, Phaseolus mungo and Vigna radiata to determine the non-toxic nature of the degraded dye metabolites (35-37). Here, V. radiata seeds were used to conduct phytotoxicity assay. Assay results revealed that the pure dye affected the germination rate of the seeds when compared to the control, while the degraded dye metabolite showed less germination rate than control but more compared to the pure dye. Similarly, shoot length was also measured and found to be highly affected by the pure dye but not with degraded dye metabolite, when compared to control.

\section{Conclusions}

Numerous researches have been carried out to counteract the dye removal problem. However, there still lies a dearth of an effective treatment system to address the issue of dye pollution. Marine environment has been known from a long time to be largely unexplored and harbors organisms producing novel secondary metabolites. Hence in this study, marine environment was used as a source for isolating azo dye decolorizing actinobacteria. Isolate VITVAMB 1 identified as Nocardiopsis sp. dassonvillei showed high decolorization potential of $\mathrm{RO}-16$ at $85.6 \%$ at a concentration of $250 \mathrm{mg} \mathrm{L}^{-1}$.

The optimum $\mathrm{pH}$, temperature, salt concentration and dye concentration were investigated. Maximum decolorization occurred at $\mathrm{pH} 8$, temperature $35^{\circ} \mathrm{C}, 3 \%$ salt concentration and $50 \mathrm{mg} \mathrm{L}^{-1}$ dye concentration. Isolate VITVAMB 1 decolorized RO-16 by biodegradation and the biodegraded metabolites were non-toxic in nature. So far, no reports have been made on the decolorization of $\mathrm{RO}-16$ by marine actinobacterium Nocardiopsis dassonvillei. The hostile marine environment might be responsible for producing novel secondary metabolite in the isolate VITVAMB 1 which was responsible for dye decolorization and biodegradation. Further, the nontoxic nature of the degraded products makes them highly potential to be applied for human welfare. 


\section{Acknowledgement}

The authors wish to thank the management of VIT University, Vellore for giving financial support in order to carry out this research work.

\section{References}

1. Bafana A, Devi SS, Chakrabarti T. Azo dyes: past, present and the future. Environ Rev. 2011;19(NA):350371. doi: 10.1139/a11-018

2. Zollinger H. Color chemistry: syntheses, properties, and applications of organic dyes and pigments. New York: $\mathrm{VCH} ; 1987$.

3. Chavan R. Indian textile industry. Indian J Fibre Textile Res. 2001;26:11-21.

4. Bafana A, Chakrabarti T, Devi SS. Azoreductase and dye detoxification activities of Bacillus velezensis strain $A B$. Appl Microbiol Biotechnol. 2008;77(5):1139-1144. doi: 10.1007/s00253-007-1212-5 pmid: 18034237

5. Shertate RS, Thorat P. Biotransformation of Textile Dyes: A Bioremedial Aspect of Marine Environment. Am J Environ Sci. 2014;10(5):489-499. doi: 10.3844/ajessp.2014.489.499

6. Seshadri S, Bishop PL, Agha AM. Anaerobic/aerobic treatment of selected azo dyes in wastewater. Waste Manage. 1994;14(2):127-137. doi: 10.1016/0956053x(94)90005-1

7. Shah K. Biodegradation of Azo dye compounds. Int Res J Biochem Biotechnol. 2014;1(2):5-13.

8. Senan RC, Abraham TE. Bioremediation of textile azo dyes by aerobic bacterial consortium. Biodegradation. 2004;15(4):275-280. pmid: 15473556

9. Bagewadi ZK, Vernekar AG, Patil AY, Limaye AA, Jain VM. Biodegradation of industrially important textile dyes by actinomycetes isolated from activated sludge. Biotechnol Bioinf Bioeng. 2011;1(3):351-360.

10. Subramani R, Aalbersberg W. Marine actinomycetes: an ongoing source of novel bioactive metabolites. Microbiol Res. 2012;167(10):571-580. doi: 10.1016/j.micres.2012.06.005 pmid: 22796410

11. McCarthy AJ, Williams ST. Actinomycetes as agents of biodegradation in the environment - a review. Gene. 1992;115(1-2):189-192. doi: 10.1016/03781119(92)90558-7

12. Pasti-Grigsby MB, Lewis TA, Crawford DL, Crawford RL. Transformation of 2,4,6-trinitrotoluene (TNT) by actinomycetes isolated from TNT-contaminated and uncontaminated environments. Appl Environ Microbiol. 1996;62(3):1120-1123. pmid: 8975606

13. Wackett LP, Brusseau GA, Householder SR, Hanson RS. Survey of microbial oxygenases: trichloroethylene degradation by propane-oxidizing bacteria. Appl Environ Microbiol. 1989;55(11):2960-2964. pmid: 2624467

14. Klausmeier R, Osman J, editors. Biodegradation of plastics by actinomycetes. Proceedings of the third International Biodegradation Symposium; 1976; London: Applied Science Publishers.

15. Zhou W, Zimmermann W. Decolorization of industrial effluents containing reactive dyes by actinomycetes. FEMS Microbiol Lett. 1993;107(2-3):157-161. doi: 10.1111/j.1574-6968.1993.tb06023.x pmid: 8472899

16. Karthik L, Kumar G, Bhaskara Rao K. Diversity of marine actinomycetes from Nicobar marine sediments and its antifungal activity. Int $J$ Pharm Pharm Sci. 2010;2(1):199-203.

17. Priyaragini S, Veena S, Swetha D, Karthik L, Kumar G, Bhaskara Rao KV. Evaluating the effectiveness of marine actinobacterial extract and its mediated titanium dioxide nanoparticles in the degradation of azo dyes. $J$ Environ Sci (China). 2014;26(4):775-782. doi: 10.1016/S1001-0742(13)60470-2 pmid: 25079407

18. Shirling EB, Gottlieb D. Methods for characterization of Streptomyces species. Int $J$ Syst Bacteriol. 1966;16(3):313-340. doi: 10.1099/00207713-16-3313

19. Singh S, Chatterji S, Nandini PT, Prasad ASA, Rao KVB. Biodegradation of azo dye Direct Orange 16 by Micrococcus luteus strain SSN2. Int J Environ Sci Technol.2014;12(7):2161-2168. doi: 10.1007/s13762014-0588-x

20. Raja MMM, Raja A, Salique SM, Gajalakshmi P. Studies on effect of marine actinomycetes on amido black (azo dye) decolorization. J Chem Pharmac Res. 2016;8(8):640-644.

21. Chakravarthy B, Vijayasree J, Swathi V, Sudhira D, Uma Maheswari Devi P. Screening and exploration of azo dye decolorizing actinomycetes from marine sediments. Int J Sci Eng Res. 2015;6(2):27-30.

22. Shobana S, hangam BT. Biodegradation and Decolorization of Reactive Orange 16 by Nocardiopsis alba Soil Isolate. J Bioremed Biodegrad. 2012;03(06). doi: 10.4172/2155-6199.1000155

23. Lakshmipathy TD, Prasad AA, Kannabiran K. Production of biosurfactant and heavy metal resistance activity of Streptomyces sp. VITDDK3-a novel halo tolerant actinomycetes isolated from saltpan soil. Biol Res. 2010;4(2):108-115.

24. Saratale RG, Saratale GD, Chang JS, Govindwar SP. Bacterial decolorization and degradation of azo dyes: A review. J Taiwan Instit Chem Eng. 2011;42(1):138-157. doi: 10.1016/j.jtice.2010.06.006

25. Mane U, Gurav P, Deshmukh A, Govindwar S. Degradation of textile dye reactive navy-blue $\mathrm{Rx}$ (Reactive blue-59) by an isolated Actinomycete Streptomyces krainskii SUK-5. Malaysian J Microbiol. 2008;4(2):1-5.

26. Lu L, Zeng G, Fan C, Ren X, Wang C, Zhao Q, et al. Characterization of a laccase-like multicopper oxidase from newly isolated Streptomyces sp. C1 in agricultural waste compost and enzymatic decolorization of azo dyes. Biochem Eng J. 2013;72:70-76. doi: 10.1016/j.bej.2013.01.004

27. Babu SS, Mohandass C, Vijayaraj A, Dhale MA. Detoxification and color removal of Congo Red by a novel Dietzia sp.(DTS26)-a microcosm approach. Ecotoxicol Environ Saf. 2015; 114:52-60.

28. Suzuki T, Endo K, Ito M, Tsujibo H, Miyamoto K, Inamori Y. A thermostable laccase from Streptomyces lavendulae REN-7: purification, characterization, nucleotide sequence, and expression. Biosci Biotechnol Biochem. 2003;67(10):2167-2175. doi: 10.1271/bbb.67.2167 pmid: 14586105

29. Molina-Guijarro JM, Perez J, Munoz-Dorado J, Guillen F, Moya R, Hernandez M, et al. Detoxification of azo dyes by a novel $\mathrm{pH}$-versatile, salt-resistant laccase from Streptomyces ipomoea. Int Microbiol. 2009;12(1):1321. pmid: 19440979 
30. Endo K, Hayashi Y, Hibi T, Hosono K, Beppu T, Ueda K. Enzymological characterization of EpoA, a laccaselike phenol oxidase produced by Streptomyces griseus. J Biochem. 2003;133(5):671-677. doi: 10.1093/jb/mvg086 pmid: 12801920

31. Mostafa M. Waste water treatment in textile Industriesthe concept and current removal technologies. J Biodivers Environ Sci. 2015;7(1):501-525.

32. Sahasrabudhe M, Pathade G. Biodegradation of azo dye CI Reactive Orange 16 by an actinobacterium Georgenia sp. CC-NMPT-T3. Intl J Adv Res 1: 91-99, 2013.

33. Saratale RG, Saratale GD, Kalyani DC, Chang JS, Govindwar SP. Enhanced decolorization and biodegradation of textile azo dye Scarlet $\mathrm{R}$ by using developed microbial consortium-GR. Bioresour Technol. 2009;100(9):2493-2500.

doi:

10.1016/j.biortech.2008.12.013 pmid: 19157864

34. Kalyani DC, Telke AA, Dhanve RS, Jadhav JP. Ecofriendly biodegradation and detoxification of
Reactive Red 2 textile dye by newly isolated Pseudomonas sp. SUK1. J Hazard Mater. 2009;163(23):735-742. doi: 10.1016/j.jhazmat.2008.07.020 pmid: 18718713

35. Sahasrabudhe MM, Saratale RG, Saratale GD, Pathade GR. Decolorization and detoxification of sulfonated toxic diazo dye C.I. Direct Red 81 by Enterococcus faecalis YZ 66. J Environ Health Sci Eng. 2014;12(1):151. doi: 10.1186/s40201-014-0151-1 pmid: 25649265

36. Ilyas S, Rehman A. Decolorization and detoxification of Synozol red HF-6BN azo dye, by Aspergillus niger and Nigrospora sp. Iranian J Environ Health Sci Eng. 2013;10(1):12. doi: 10.1186/1735-2746-10-12 pmid: 23369298

37. Lade H, Govindwar S, Paul D. Low-Cost Biodegradation and Detoxification of Textile Azo Dye C.I. Reactive Blue 172 byProvidencia rettgeriStrain HSL1. J Chem. 2015;2015:1-10. doi: $10.1155 / 2015 / 894109$ 